\section{$\underset{\text { hommes }}{\text { \& migrations }}$}

\section{Hommes \& migrations}

Revue française de référence sur les dynamiques

migratoires

\section{$1308 \mid 2014$}

Les Paris des migrants

\title{
Minh Tran Huy, Voyageur malgré lui
}

Paris, Flammarion, 2012, $18 €$.

\section{Élisabeth Lesne}

\section{(2) OpenEdition}

1 Journals

\section{Édition électronique}

URL : http://journals.openedition.org/hommesmigrations/3044

DOI : 10.4000/hommesmigrations.3044

ISSN : 2262-3353

\section{Éditeur}

Musée national de l'histoire de l'immigration

\section{Édition imprimée}

Date de publication : 1 octobre 2014

Pagination : 201

ISBN : 978-2-919040-29-2

ISSN : 1142-852X

\section{Référence électronique}

Élisabeth Lesne, «Minh Tran Huy, Voyageur malgré lui », Hommes \& migrations [En ligne], 1308 | 2014, mis en ligne le 10 juillet 2015, consulté le 24 septembre 2020. URL : http://journals.openedition.org/ hommesmigrations/3044; DOI : https://doi.org/10.4000/hommesmigrations.3044

Ce document a été généré automatiquement le 24 septembre 2020.

Tous droits réservés 


\title{
Minh Tran Huy, Voyageur malgré lui
}

Paris, Flammarion, 2012, $18 €$.

\author{
Élisabeth Lesne
}

\section{RÉFÉRENCE}

Minh Tran Huy, Voyageur malgré lui, Paris, Flammarion, 2012, 230 pages.

Comment raconter d'où l'on vient, de quel monde, de quelle culture, de quels silences, sans écrire son autobiographie? Minh Tran Huy, née en France de parents venus du Viêtnam dans les années 1960, a choisi le détour de la fiction.

Dans Voyageur malgré lui, Line, la narratrice, prend quelques jours de congé à New York et découvre dans un musée l'existence d'Albert Dadas, un ouvrier gazier du $\mathrm{XX}^{\mathrm{e}}$ siècle qui souffrait de dromomanie ou de la folie du fugueur. Cette étrange maladie lui faisait tout quitter dans une espèce de transe semi-somnambulique pour voyager avec frénésie. Line, qui aime fréquenter les musées et se concentrer sur autre chose que les bruits du monde qu'elle enregistre pour une agence de création sonore - c'est son métier -, va se passionner pour ce premier cas de "tourisme pathologique" et se plonger dans l'étude qu'un médecin lui a consacrée. Mais très vite lui reviennent les souvenirs d'autres voyageurs malgré eux: Samia Yusuf Omar, cette jeune sprinteuse somalienne qui a enflammé les Jeux olympiques de Pékin en 2008 avant de périr noyée pour avoir tenté d'émigrer, et aussi des membres de sa propre famille, à commencer par Thin, l'oncle bizarre, qui avait traversé plusieurs océans et continents "tout en rêvant de rentrer chez lui pour n'en plus bouger, et ce désir était si fort, sa détresse si violente, qu'ils en avaient détruit sa raison". Sa mort avait pour la première fois provoqué quelques confidences de son père, dont l'élément naturel était le silence sur sa vie d'avant l'exil : "Au détour de mon enfance resurgissait, parfois, celle de mon père, qui s'échappait de sa mémoire comme une rivière déborde de son lit. Ces occasions étaient rares, le mensonge par omission lui était plus familier." Pas étonnant que sa fille rêve de "collectionner les différentes formes de silence". 
Dans la deuxième partie pourtant, alors que Line vole vers la France, consciente que voyager librement est un privilège réservé à ceux qui détiennent "les papiers adéquats obtenus sans rien faire d'autre que de naître au bon endroit, au bon moment", se déroule un récit à deux voix de l'histoire familiale. À celle de la jeune femme se mêle celle de son père, qui, alors que la mémoire commençait à le quitter, éprouva soudain une urgence à raconter sa jeunesse dans un pays déchiré par les guerres, contre les Français, puis contre les Américains: "le présent m'échappe comme il m’a toujours échappé (...), le passé continue de vivre en moi (...) : mes morts sont demeurés dans mon cœur et mon âme quand bien même je m'interdisais de les évoquer, m'accompagnant dans chacun de mes gestes, chacune de mes pensées".

5 Si sa silhouette élégante, son exigence bienveillante sont présentes dès les premières pages, c'est "son passé de langueur et d'anémie" que l'on découvre ensuite, la rage de réussir d'un petit paysan orphelin du Nord-Viêtnam qui est devenu ingénieur français, le sort tragique de ses compagnons d'études et, plus tard, le constat que partagent nombre d'exilés: "Presque malgré nous, nous commencions de nous établir en ces lieux où nous n'avions pensé que passer. Nous commencions de construire une existence, et même de la prolonger: ta scur a vu le jour (...) et trois ans après, tu es né." Sans oublier le prix à payer : l'impression de n'être chez soi nulle part, le "double exil", comme l'appelle Abdelmalek Sayad.

6 Le livre refermé, on se prend à penser que Minh Tran Huy a adopté le même cheminement que ce père si discret, si pudique, en le révélant lentement - n'a-t-il pas mis plus de deux décennies à parler de lui ? On ne peut qu'être ému par cette constellation de destins dont il risquait de ne rien rester. Le roman se dresse contre la fatalité de l'effacement, s'interroge de façon délicate sur la transmission et révèle toute la richesse des identités faites d'un mélange de langues et de cultures.

\section{AUTEURS}

\section{ÉLISABETH LESNE}

Responsable du Prix littéraire de la Porte Dorée 